\title{
IDENTIFICATION OF RESIDUAL IMPURITIES IN Si-DOPED MBE GROWN GaAs
}

\author{
M. Kaniewska, K. Regińsiri, J. Kaniewski, J. Muszalski, L. ORnoch, \\ J. Adamczewska, J. Marczewski, M. Bugajski
}

Institute of Electron Technology Al. Lotników 32/46, 02-668 Warszawa, Poland

AND E. Mizera

Institute of Physics, Polish Academy of Sciences

Al. Lotników 32/46, 02-668 Warszawa, Poland

\begin{abstract}
The changes of dopant vaporization enthalpy in GaAs:Si grown by molecular beam epitaxy revealed the presence of residual donors related to group VI elements. This has been confirmed by deep level transient spectroscopy studies of AlGaAs:Si layers grown in the same MBE system. It is argued that a commonly observed deep trap labelled E2 is probably related to Te, Se or S. The measurements have been performed on near-ideal Al Schottky barriers grown in situ by MBE.
\end{abstract}

PACS numbers: $73.40 . \mathrm{Ns}, 71.55 . \mathrm{Eq}, 73.20 . \mathrm{Hb}$

It is generally accepted that $\mathrm{Si}$ is an almost ideal dopant for $n$-type GaAs grown by molecular beam epitaxy (MBE). At present the layer doping is still largely empirical and often, at low doping levels residual impurities disturb calculated dependences. Usually shallow acceptors can be readily identified by low temperature photoluminescence measurements. The chemical identities of shallow donors are more difficult to determine by simple methods, and resort has to be made to far-infrared photothermal ionization or very high resolution Zeeman photoluminescence studies.

In this paper we discuss an unintentional co-doping process during the growth of GaAs:Si by MBE. Thick epitaxial layers of GaAs were grown at $580^{\circ} \mathrm{C}$ on semi-insulating (001) oriented GaAs using the Riber 32P MBE system, which has a background pressure $<1 \times 10^{-10}$ torr. High purity $\mathrm{Ga}(7 \mathrm{~N})$, As $(7 \mathrm{~N})$ and $\mathrm{Si}$ ( $<10^{12} \mathrm{~cm}^{-3}$ intrinsic) source materials were used. To achieve a full range of $\mathrm{Si}$ concentration the temperature of $\mathrm{Si}$ effusion cell was changed from $550^{\circ} \mathrm{C}$ to $1130^{\circ} \mathrm{C}$, whereas those of $\mathrm{Ga}$ and As were held constant at $945^{\circ} \mathrm{C}$ and $218^{\circ} \mathrm{C}$, respectively. The beam equivalent pressure $\mathrm{As} / \mathrm{Ga}$ ratio was equal to 9.5 . All layers were grown at constant rate $1 \mu \mathrm{m} / \mathrm{h}$. Electrical properties of the epitaxial layers were characterised by Van der Pauw measurements. The effects of surface and 


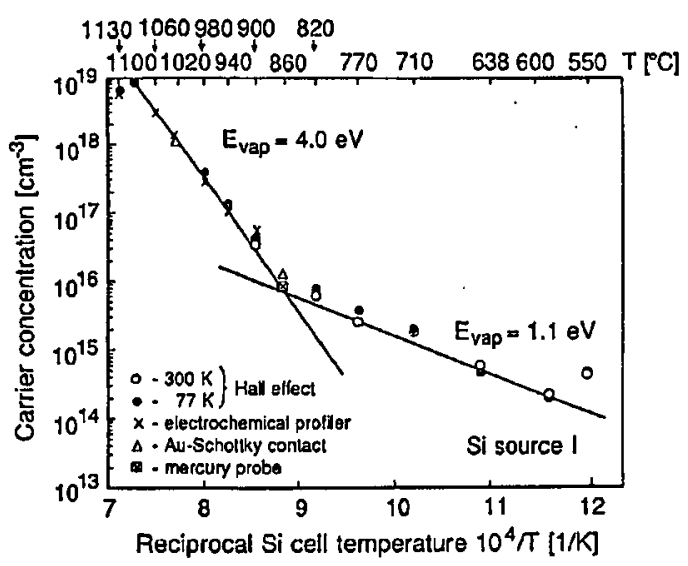

Fig. 1. Electron concentration versus reciprocal temperature of Si cell for MBE GaAs:Si with $T_{\text {sub }}=580^{\circ} \mathrm{C}$.

interface depletion layer have been taken into account. Net donor concentration at room temperature was also determined from $C-V$ characteristics either by use of the Bio-Rad electrochemical profiler or conventional Au Schottky diodes.

Since $I_{\mathrm{Si}}=K \exp \left(-E_{\mathrm{vap}} / k T\right)$, where $I_{\mathrm{Si}}$ is the Si flux and $E_{\mathrm{vap}}$ is its enthalpy of vaporization, the proportionality between $\mathrm{Si}$ flux $I_{\mathrm{Si}}$ and the donor concentration can be demonstrated most readily by establishing that an exponential dependence exists between the donor concentration and the $\mathrm{Si}$ source temperature. This is seen in Fig. 1, from which the value of $E_{\text {vap }}$ at a concentration higher than $1 \times 10^{16} \mathrm{~cm}^{-3}$ is determined to be $4.0 \mathrm{eV}$, which is close to the commonly accepted value of $4.1 \mathrm{eV}$. However, at lower concentrations the enthalpy is reduced noticeably, indicating the presence of residual donors. A value determined, being cqual to $1.1 \mathrm{eV}$, is close to vaporization enthalpy for VI group elements, i.e., $\mathrm{S}(0.9 \mathrm{eV})$, Se $(1.0 \mathrm{eV})$ and $\mathrm{Te}$ $(1.2 \mathrm{eV})$. It is well known that these elements exhibit the DX behaviour and can be detected in $\mathrm{Al}_{x} \mathrm{Ga}_{1-x} \mathrm{As}, x>0.2$ as deep states. In order to confirm the presence of residual donors in our growth environment deep level transient spectroscopy (DLTS) studies have been performed on special test structures.

The investigations have been carried out on near-ideal Al Schottky barriers produced by MBE on the top of the following structures: $0.5 \mu \mathrm{m} n$-type buffer layer doped to $2 \times 10^{18} \mathrm{~cm}^{-3}, 10$ period GaAs-AlGaAs superlattice $(0.1 \mu \mathrm{m}$ thick), $0.1 \mu \mathrm{m}$ undoped graded $\mathrm{Al}_{x} \mathrm{Ga}_{1-x}$ As layer and $3 \mu \mathrm{m} \mathrm{Al}_{0.3} \mathrm{Ga}_{0.7}$ As layer doped with $\mathrm{Si}$ to the level $2.5 \times 10^{16} \mathrm{~cm}^{-3}$. The superlattice was introduced to improve a quality of layers by preventing entering of extended defects into the $\mathrm{Al}_{0.3} \mathrm{Ga}_{0.7} \mathrm{As}$ layer. After the termination of the layer growth a clear $(3 \times 1)$ reconstruction of As stabilised surface was observed by means of reflection high energy electron diffraction (RIIEED) technique. Next the temperature of substrate was lowered to $20^{\circ} \mathrm{C}$ at chamber overpressure better than $4 \times 10^{-10}$ torr and the $\mathrm{Al}$ metallic layer was deposited at pressure $5 \times 10^{-11}$ torr at the rates: first $3 \AA-0.01 \AA / \mathrm{s}$ and the following $0.2 \mu \mathrm{m}-0.2 \mu \mathrm{m} / \mathrm{h}$. Ex situ observations of RHEED patterns and double crystal X-ray diffraction showed that the Al layer had a (001) oriented 
single crystal structure. The determined [110] crystallographic direction of Al unit cell is aligned with the [100] direction in $\mathrm{GaAs}$ unit cell. In order to estimate the $\mathrm{Al}$ crystal perfection, the symmetric 002 and asymmetric 113 rocking curves were measured. The half-width (FWHM) of the 002 rocking curve was $20^{\prime}$ due to a slightly mosaic structure and a small thickness $(0.2 \mu \mathrm{m})$ of the layer.

The electrical quality of the Schottky diodes was tested by means of currentvoltage $(I-V)$ and capacitance-voltage $(C-V)$ measurements. $I-V$ forward characteristics, accurately exponential over 9 decades have been measured. The ideality factor $n=1.030 \pm 0.005$ at a wide temperature range, from $275 \mathrm{~K}$ to $340 \mathrm{~K}$, have been determined. The excellent quality of Schottky contacts allowed us to determine the barrier height $\varphi_{\mathrm{b}}$ from $(I-V)$ vs. $T$ and $C-V$ characteristics [1]. The contributions from $\Gamma, L$ and $X$ minima have been taken into account [2]. It has been found for $\mathrm{Al} / \mathrm{Al}_{0.3} \mathrm{Ga}_{0.7} \mathrm{As}$ Schottky contact $\varphi_{\mathrm{b}}^{I-V}=1.07 \mathrm{eV}$ and $\varphi_{\mathrm{b}}^{C-V}=1.14 \mathrm{eV}$. The obtained values are similar to that obtained by Missous et al. at a slightly lower Si concentration [3].

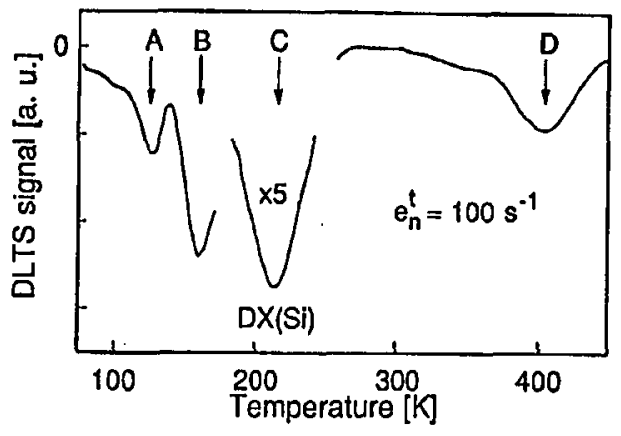

Fig. 2. DLTS spectra of $\mathrm{Al}_{0.3} \mathrm{Ga}_{0.7} \mathrm{As}$ :Si MBE layers obtained at pulse duration time $50 \mu \mathrm{s}$ and emission rate $e_{n}^{t}=100 \mathrm{~s}^{-1}$.

The same test structures were used for DLTS studies performed at a constant voltage as well as constant capacitance modes. A typical DITS spectrum for majority carrier pulses is illustrated in Fig. 2. Four deep levels labelled $A-D$ have been detected in a temperature range from $77 \mathrm{~K}$ to $450 \mathrm{~K}$. Their thermal activation energies $\Delta E$ and concentrations $N$ determined from emission characteristics are as follows: $\Delta E^{A}=(0.21 \pm 0.02) \mathrm{eV}, N^{A}=4 \times 10^{13} \mathrm{~cm}^{-3}, \Delta E^{B}=(0.26 \pm 0.02) \mathrm{eV}$, $\Delta E^{C}=(0.42 \pm 0.02) \mathrm{eV}, \Delta E^{D}=(0.79 \pm 0.01) \mathrm{eV}, N^{D}=3 \times 10^{13} \mathrm{~cm}^{-3}$. The energies of states $A$ and $B$ were determined at low emission rates, when they were well separated from the trap $C$. The dominant trap $C$ is clearly related to the well-known DX (Si). The trap $D$ observed at a low concentration has been identified as $\mathbf{E} 6$ which is related to a complex associated with $\mathrm{Ga}$ vacancy and an oxygen atom [4] or an Al-O complex [5]. The traps $A$ and $B$ well fit to unidentified levels labelled $\mathrm{E} 1$ and $\mathrm{E} 2$ that were often observed in AIGaAs grown by MBE [6]. On the other hand the $\operatorname{trap} B$ fits with high accuracy to the level related to DX ( $\mathrm{Te}$ ) $(\Delta E=0.27 \mathrm{eV})$, studied by Dobaczewski et al. [7]. However, its relation to $\mathrm{S}$ or 
Se is also possible since the thermal activation energy $(\Delta E \approx 0.28 \mathrm{eV})$ as well as the DLTS peak position are the same for all group VI elements [8].

The measurements of DLTS peak height vs. pulse duration time $t_{\mathrm{c}}$ for all the traps studied have also been performed. It has been found that the peak height of the traps $A$ (E1) and $D(\mathrm{E} 6)$ were almost unchanged when $t_{\mathrm{c}}$ was reduced to $1 \mu \mathrm{s}$, showing a high value of capture cross sections of these states. In contrast to that, the peak height of traps $B$ and $C(\mathrm{DX}(\mathrm{Si}))$ were significantly reduced at short pulses.

The results obtained from DLTS studies for level $B$ and the determined value of vaporization enthalpy suggest that this trap is related to the group VI element. It should be noticed that in such a case a concentration of the trap determined from DLTS is underestimated due to its DX character. The correspondence of the trap $B$ to the level $\mathrm{E} 2$ indicates a common MBE problem of the presence of traces of these impurities in the growth environment.

This work was supported by the State Committee for Scientific Research (Republic of Poland), grant PBZ-101-01-11.

\section{References}

[1] E.H. Rhoderic, Metal-Semiconductor Contacts, Clarendon Press, Oxford 1978.

[2] S. Adachi, J. Appl. Phys. 58, R1 (1985).

[3] M. Missous, W.S. Truscott, K.E. Singer, J. Appl. Phys. 68, 2239 (1990).

[4] S. Naritsuka, K. Yamanaka, M. Mannoh, M. Mihara, M. Ishi, Jpn. J. Appl. Phys. 24, 1324 (1985).

[5] K. Akimoto, M. Kamada, K. Taira, M. Arai, N. Watanabe, J. Appl. Phys. 59, 2833 (1986).

[6] K. Hikosaka, T. Mimura, S. Hiyamizu, Conf. Ser. Inst. Phys. 63, 233 (1981).

[7] L. Dobaczewski, P. Kaczor, M. Missous, A.R. Peaker, Z.R. Żytkiewicz, Phys. Rev. Lett. 68, 2508 (1992).

[8] O. Kumagui, H. Kawai, Y. Mori, K. Kaneko, Appl. Phys. Lett. 45, 1322 (1984). 